\title{
Black Box Royalties Are Coming Courtesy of the Music Modernization Act: Lessons from the Early Years of SoundExchange
}

\author{
John L. Simson \\ American University \\ This paper was presented at the 2019 International Summit of the \\ Music \& Entertainment Industry Educators Association \\ March 21-23, 2019
}

https://doi.org/10.25101/19.30

\section{Abstract}

The passage of the Music Modernization Act has rightfully been heralded as a major advance for the music industry. Divided into three parts, the Act corrected a decades long problem by providing limited protection to pre-1972 recordings enabling legacy artists a right to be paid when non-interactive streaming services stream their recordings, attempted to fix a problem for producers of pre-1996 sound recordings who were having difficulty collecting royalties from SoundExchange, and most importantly made a major change in the way that on-demand streaming services license musical compositions under the Copyright Act's section 115 compulsory license. This significant change in licensing creates a blanket license for compositions and a new collecting society, "the MLC," to collect and distribute these royalties. It will end five plus tumultuous years of litigation against Spotify and other streaming services for their failures to abide by the laws of the old section 115 and enable these services to stream more efficiently. It will also end a game played by these services which robbed songwriters and music publishers of millions of dollars in royalties. One byproduct of this new change in the law will be the accumulation of undistributed royalties as tracking down songwriters and music publishers will not always be easy. SoundExchange was the first experiment in this kind of system: having to pay everyone in the world and not just those who sign up to be your members (as is typical for most performing rights organizations.) SoundExchange's experience, which will have some similarities and some very distinct differences, was that $80 \%$ of participants were easy to track down and pay while $20 \%$ were quite difficult. This paper explores those similarities and differences and explain what techniques can be used to minimize black box royalties.
Keywords: Music Modernization Act, SoundExchange, music copyright, mechanical royalties, compulsory license, music streaming, black box royalties. Music Licensing Collective

The Music Modernization Act (MMA) has been heralded as a major victory for the creative community and it should be! It will provide benefits to three different constituencies: songwriters and music publishers, recording artists who released recordings prior to February 15, 1972, and music producers, mixers or sound engineers who produced recordings prior to November 1, 1995.

While the benefits of the MMA are important and certainly justify the time and effort spent on its passage, there are some sobering realities that all must face and frankly should expect going forward: the first, is that there will be a large pile of cash that will be very hard to distribute. This undistributed money, either caused by insufficient or erroneous data or the failure of those entitled to royalties to come forward and identify themselves is typically referred to as black box money.

In a June 26, 2019 hearing on Capitol Hill, Register of Copyrights, Karyn Temple, was questioned by members of Congress about the breadth of black box royalties which the new Music Licensing Collective (MLC) will be charged with distributing. Some industry estimates have put the number at over two and a half billion dollars! ${ }^{1}$ Ms. Temple assured members of Congress that although some of these revenues date back to 2014, the earliest distribution of these unmatched royalties would be 2023 . Nearly all collective organizations (CMOs) have black box money. If SoundExchange's early days are any indicator, more than twenty percent of the royalties collected will be very difficult to 
distribute! ${ }^{2}$

In this paper I will examine why black box royalties are inevitable. I will also provide recommendations for the $\mathrm{Mu}-$ sic Licensing Collective, the new licensing collective created by the MMA, to ensure that the distribution of these undistributed royalties is done in the most fair and ethical manner.

Nearly twenty years ago in 2001, SoundExchange performed its first distribution. Another landmark piece of music legislation had been passed in 1995, the Digital Performance Right in Sound Recordings Act (DPRA) which created the first performance right for U.S recording artists and record labels and mandated that commencing upon February 1, 1996, non-interactive services streaming sound recordings over cable, satellite, or internet had to pay royalties to sound recording copyright owners (SRCOs) and both featured and non-featured recording artists. ${ }^{3}$ From February 1, 1996 to December 31, 2000, music services paid royalties into escrow waiting for an organization to be formed that could distribute these royalties. ${ }^{4}$ Music Choice, Muzak, and DMX were the original three services paying royalties into escrow as they all used digital means of transmitting music to consumers either over DirecTV, DishNet, or cable television systems. Internet streaming was still nascent and of little commercial value.

During that initial five-year period, there was approximately $\$ 6.3$ Million in royalties paid into an escrow account by these early providers. SoundExchange wasn't even on the horizon when these collections started. When SoundExchange was in its formative years in 2000, it was decided that they would cap their administrative fee at twenty percent of collections even though that wouldn't cover their costs. The organization felt that twenty percent was in line with what other small societies were charging their members. This twenty percent share of that initial escrow meant that SoundExchange would have approximately $\$ 1.26$ Million from collected royalties to build the collecting society, including staffing, building the technology required to perform the tasks or outsourcing it from another vendor, as well as paying for rate setting proceedings. By comparison, in the early years of ASCAP an initial distribution of $\$ 80,000$ was made on collections of over $\$ 600,000^{5}$ as they did not have a backstop to subsidize early start-up costs. ${ }^{6}$

Fortunately, SoundExchange had the support of the major labels through their trade association, the Recording Industry Association of America (RIAA) and was able to spend well more than $\$ 1.2$ Million to build systems and technology required to accomplish these distributions. However, due to concerns about excessive costs in those early years, when streaming projections were woefully low, head count suffered and the organization was completely understaffed for certain essential tasks. ${ }^{7}$
With a skeletal staff and very modest collections, SoundExchange completed its first distribution in late 2001. Their experience was that it was easy to pay $70 \%$ to $80 \%$ of recording artists and about the same on the label side (the majors were about $70 \%$ themselves and major indies another $10 \%)$ leaving smaller indies and self-released artists as the final $20 \%{ }^{8}$ These participants were far more difficult to track down and sometimes even harder to pay.

The new MLC will have several benefits that SoundExchange did not have in those early years. First, mechanical rights are well-established and well-known among the music publishing community. The first digital performance rights for recording artists and sound recording copyright owners passed in 1995 and was not on anyone's radar. When managers, business managers, and entertainment attorneys were contacted by SoundExchange staff, to let them know about their client's royalties, many were disbelieving. Staff often heard, "there are no performance rights for artists in the U.S," which had long been the case. That shouldn't be the case with mechanicals which have been around since 1909 !

Second, the MLC will be funded by the digital service providers (DSPs) either at a level that is mutually agreed upon between the DSPs and the music publishing community or at a funding level set by the Copyright Royalty Board (CRB) and should be much greater than SoundExchange had at its disposal in the early years, as the royalty expectations are much, much greater for the MLC, even with the prospect of significant direct licensing diminishing MLC collections. ${ }^{9}$

Collecting societies are a fixed cost business: you have to build systems and spend a significant amount of money on technology and staffing - but the more revenue you put through your system, the lower the administrative cost becomes. That was true at SoundExchange where admin fees quickly dropped from the fixed $20 \%$ fee adopted in the early years, where they lost money each year, to sub-10\% and then sub-5\% admin fees over the next decade as collections grew dramatically. But black box money grew as well despite best efforts to resolve data issues and the organizations' search for missing rights owners and recording artists.

It is no surprise to anyone in the music industry that one of the greatest contributors to black box revenue growth is the lack of a global repertoire database that spells out ownership of both the sound recordings and the underlying compositions contained on those recordings. ${ }^{10}$ While our industry does have ISWC and ISRC codes, which should be helpful in making distributions easier, they are not universally used, especially by smaller players, who are the most difficult to find and pay. ${ }^{11}$

SoundExchange and the new MLC will share one major characteristic: when one compares the SoundExchange ex- 
perience to ASCAP, BMI, SESAC, GMR, or many other collecting societies, it is actually not like comparing apples to oranges, but more like apples to gorillas. All of the publishing PROs mentioned represent only their members and only collect on behalf of their members and only pay their members. To join these societies, you must tell them what you own and your relative share of each composition when you register. At the end of each year, these societies divide up the money among their members and theoretically shouldn't have any black box money. Checks may come back as uncashed as someone may have moved, but for the most part it should be simple. For SoundExchange, there was no membership requirement; there was no requirement that artists or labels tell the organization what they owned or how they split royalties. SoundExchange was an experiment on a whole different level. They had to find everyone in the world and pay them. ${ }^{12}$ Additionally, the data of who they were supposed to pay was provided by the services playing the recordings and their motivation to provide accurate data was sorely lacking. And SoundExchange made that worse by demanding complete census data of every single recording!

You may wonder how census data made things more difficult. While it was the right thing to do in their effort to ensure that every play was recognized and paid, it meant that every mistake in data was magnified. ASCAP and BMI were using sampled data to distribute their public performance royalties, broadcasters only provided three days of data in each calendar quarter, so most mistakes in data entry would simply disappear. When internet services tried to insist that SoundExchange accept the same three-day sample, the organization fought back illustrating how many artists and titles would disappear: online music was fundamentally different than over-the-air radio playlists which were short and repetitive. SoundExchange research showed that $41 \%$ of titles and $26 \%$ of artists would disappear in a sampling of data. The Copyright Office supported SoundExchange's position and census data became the rule. ${ }^{13}$

Some early major hurdles were clarifying ownership issues between distributors and owners. Oftentimes the service playing the music would report the distribution label rather than the sound recording copyright owner. Additionally, ownership of masters changed hands frequently with majors buying independents and independents buying other independents as well as exclusive licensing arrangements ending and the recapture of rights by labels which had previously assigned rights to another company. Territorial issues also presented problems. In an industry that had been created around physical borders, some recordings were owned by a specific label in a specific territory but owned by another label in a different territory. ${ }^{14}$ Another issue concerned socalled "gray market" recordings: labels in the E.U. and U.K. took advantage of shorter periods of protection for sound recordings by taking public domain recordings and reissuing them. Frequently, a streaming service would stream from those public domain reissues and report to SoundExchange that Bear Family or Ace were the owners. While they were the owners of those reissues outside the U.S., the rights in the U.S. were typically still owned by the original label as the term of protection here was much longer. ${ }^{15}$

These copyright term issues shouldn't affect the MLC in the same way as copyright terms for compositions are fairly uniform around the world, unlike sound recordings. However, the MLC will have far greater problems than SoundExchange had in several other areas:

First: most recordings are owned by one record label or artist, while most compositions have multiple owners and ownership shares are frequently unequal.

Second: many compositions get released on recordings before there is even an agreement as to how to split royalties among the writer and publisher participants, resulting in compositional share claims of over $100 \%$ ! How does the MLC resolve such claims? Is the money placed in escrow until writers and publishers agree upon the appropriate splits? Are these royalties subject to black box treatment if splits are never agreed upon or are they held in escrow until an agreement is reached?

Third: while SoundExchange frequently received reports of use indicating that the featured artist was "Various Artists" (typically from a compilation or soundtrack which featured various artists), the MLC is likely to have reports of use for "Bonus Track" or incomplete song title information which may make it impossible to determine which composition was being streamed. (Both SoundExchange and the MLC will face issues regarding multiple versions of the same recording/composition where a particular remix may add an additional author/publisher if a rap is added, for example.) The MLC will not however share SoundExchange's problem determining who to pay on live recorded versions of a composition which features different players on the live vs. the studio version! ${ }^{16}$ Both organizations will also face the challenge created by foreign works, many of which will be reported in their language and in characters that may not be recognized by a database. ${ }^{17}$

Fourth: the MLC will face a daunting task in that licenses for each on-demand service streaming compositions may have different publishers based upon license termination dates. It is entirely possible that one publisher will be entitled to mechanical royalties and another publisher will be entitled to public performance royalties on the same stream.

All of these issues add up to undistributed royalties: the black box. How should these royalties be distributed? Every day there are more complaints registered in the music industry press about how the major music publishers are 
going to swallow the black box money based upon their market share even though they have direct licenses with the major streaming services which provide that the streaming services pay them directly for usage. ${ }^{18}$

Why should major publishers share in black box revenue if they direct license? Given how much more valuable content they own, the likelihood is that a large percentage of data issues that prevent payments will concern compositions owned in whole or part by major publishers. Direct licenses with services may cut down on bad data entry, especially if there is a closed system where the streaming services are provided accurate information about ownership from the respective publishers and record labels, but remember, the streaming services are focused far more on the recording artist than they are on who wrote the underlying compositions, and errors are likely.

Another complaint often read in industry publications is that the major publishers have built in "digital breakage" so they are already being compensated for losses due to bad data. While major publishers may have the leverage to require guaranteed quarterly payments, which may exceed actual usage, which thus result in a "windfall" to the publisher, or at least a rate that is higher than the mechanical specified in Section 115, unless that overage results in underpayments to independent publishers and writers, it should not be a substitute for participating in black box royalties. If publishers are sharing this breakage with their writers, and most major publishers have indicated that they will, this is a win for songwriters and should not be a bar to participating in the distribution of black box royalties.

One additional complaint recently lodged concerns the special language in the MMA statute that provides that royalties which are unpayable by the MLC will not be subject to escheat to the state and will instead be distributed by the MLC to other music publishers and songwriters. The complaint is that were these royalties escheated to the state, the state would then hold these royalties for the music publisher entitled to them for a longer period of time. There are several significant problems with this argument. First, the publisher may not be sufficiently identified so the MLC doesn't know who they are or what state they are located in. Second, it is far better that the royalties be distributed within the music community, on a pro rata basis, then to let the state keep the money after a period of time if the publisher never comes forward to claim their money. SoundExchange was the first organization to use the Supremacy Clause in this way. How do you escheat money payable to "Various Artists?" To "Mozart?" SoundExchange used this money to offset costs of administration, which meant that it was equally shared by all recipients in the system. As the MLC's costs are being paid for by the DPS, this is not an option, so increasing everyone's distributions in relative shares is the appropriate action to take.

\section{Some Recommendations for the MLC in Distributing Black Box Money}

First, as this is a new mechanism for distribution of mechanical royalties, efforts must be made to publicize the need for independent publishers and self-published songwriters to register with the MLC. While the PROs should take the lead on this, as well as independent distributors like TuneCore, Audiam, DistroKid, The Orchard, and others, the DSPs must also establish a process for sending out notices when independent tracks are being played. ${ }^{19}$ Songwriters whose works are being performed on streaming services are the ones most likely to listen to the track or be alerted that it is being performed. It will be far more powerful and impactful if a performance were accompanied by a message that royalties were being accrued based upon the performance and that here is the link to collect them. The DSPs control the pipes to hundreds of millions of listeners with a much more direct connection for dissemination of this important information to independent songwriters and small publishers.

Second, time is required. The current law provides at least a three-year period prior to the distribution of black box royalties. ${ }^{20}$ SoundExchange waited five years before its first pool release of undistributed royalties and I'd recommend that the MLC do the same. What's the rush? The MLC's costs have been paid for by the DSPs - so it's not about recovering the money required to build the MLC; and the longer the MLC gives independent publishers and writers to register, the more legitimacy will be earned by the MLC in trying to do the right thing: to see that those entitled receive their payments.

Time will also result in better data as the MLC will have time to attack bad data and correct it; songwriters and publishers will have the opportunity to search the database and find their works and correct errors, and help identify works that are not attributed to anyone. This will only help the MLC in their quest to build a global repertoire database which is required under the MMA.

Third, while it is always preferable that all royalties be distributed based upon actual data to the publisher/songwriter who has earned them, there will be instances when data is unavailable or insufficient. In such instances, "rough justice" or proxy distributions will be necessary. ${ }^{21}$ When calculating the distribution of black box royalties, in such distributions, I would recommend creating two separate pools for distribution: a) Pool Number One is comprised of bad or insufficient data - work has been done to identify repertoire but it becomes clear that identification is not possible; and, b) Pool Number Two is comprised of identified works whose owners/authors have not come forward 
to claim them and the MLC, after significant effort, has not been able to pay them. ${ }^{22}$

My reason for dividing the black box royalties into two pools is simple: since we can't identify the works in Pool Number One, they are likely to be comprised of works that would be representative of the overall pool of publishers and songwriters without regard to direct licensing and should be distributed based upon market share regardless of direct licenses. Pool Number Two, on the other hand, is comprised of works that have been identified and don't belong to any of the major publishers and songwriters, nor any of the members licensing all of their works through the MLC. For this pool, distribution should be based upon everyone's relative share passing through the MLC. Thus, if Publisher A has a market share of twenty-five percent but only has five percent of the total royalties passing through the MLC due to direct licensing, they would receive twenty-five percent of Pool Number One but only five percent of Pool Number Two.

Every collective management organization (CMO) has to balance carefully competing goals: accuracy and efficiency. Accuracy is measured in payments to the right players while efficiency is typically measured in "admin" rates: ${ }^{23}$ the rate it costs to perform the essential tasks of the CMO. It is unsustainable and bad business practice for a CMO to spend five hundred dollars to track down someone owed five! As such, despite best efforts, there will be significant undistributed royalties during the early years of the MLC, and the manner of its distribution will provide controversy no matter how much effort is spent attempting to do this transparently-and no matter how much effort has been spent to track down each and every entitled recipient.

To remain efficient, the MLC must "follow the dollar" in attempting to track down unidentified writers and publishers. This means they must start by trying to track down those who are owed the most and then work their way down the list. There is a point where the MLC should stop. While the MLC should always be willing to register any publisher who comes forward, no matter how much or little they are owed, resources should not be wasted on searching for low earners. There are exceptions to this rule and SoundExchange created a model that the MLC should use. SoundExchange was very active reaching out to industry organizations where they thought they might find recording artists and/or record labels owed royalties. They engaged in "matching activities" where they would match their unpaid list against the list of members of those organizations. This was a very effective exercise and resulted in thousands of matches, many of whom were low dollar recipients. The organization working with SoundExchange would notify their membership of the match and provide their members with information on registering to receive their royalties. The
MLC should endeavor to do the same.

The MLC should take all reasonable steps to match money with those entitled. When all else fails, and money falls into the black box, I hope the rules set forth above provide a framework for the MLC to distribute these royalties in a manner that will satisfy the music community at large and not just the largest in the music community.

\section{Endnotes}

1. Former TuneCore founder and current Audiam CEO, Jeff Price, has stated that the 2014-2019 undistributed pool may be more than four billion dollars. Congresswoman Sheila Jackson Lee, in questioning Temple, mentioned this amount. Reported in Billboard, June 26, 2019.

2. The percentage of "hard to distribute" royalties may increase dramatically if many major publishers direct license their work around the Music Licensing Collective, thereby removing the "easy to distribute" royalties from the mix which will decrease pay through rates and increase the percentage of royalties that are undistributed.

3. Featured recording artists were to be paid $45 \%$ of royalties while non-featured recording artists were to be paid 5\% through a fund jointly created by the American Federation of Musicians (AFM) and the American Federation of Television and Radio Artists (AFTRA), now known as the SAG/AFTRA/AFM Intellectual Property Fund.

4. It is important to distinguish this new right for those owning and performing on sound recordings from those who created and owned the underlying compositions. ASCAP, BMI, SESAC, and GMR in the United States represent the interests of music publishers and songwriters. SoundExchange and Royalty Logic, Inc., a now defunct but early competitor to SoundExchange, represented the interests of SRCOs and featured recording artists.

5. Russell Sanjek, Pennies from Heaven: The American Popular Music Business in the Twentieth Century (New York: Da Capo Press, 1996). This book is a must for any student interested in the history of performing rights. 
6. Section 114 of the U.S. Copyright Act initially provided that a designated agent such as SoundExchange would collect royalties and then pay $95 \%$ to the owner of the sound recording copyright, typically a record label, who would then "allocate" $45 \%$ of the royalties to the featured recording artist. Recording artists were upset when they fully realized that direct payment of the artist's share was not required, and there was an outcry. ASCAP and BMI divided money between music publisher and songwriter and that was the model the industry was used to on performance royalties. SoundExchange was able to obtain the provisional agreement from the major record labels (EMI, SONY, WMG, UMG, and BMG) to pay their artists directly on an experimental basis. The law was changed in 2003 to require direct payment of the featured artist's share.

7. Initial projections by business development consultants, procured by the RIAA, estimated 2010 collections to be $\$ 80$ million. Actual collections in 2010 were more than three times that estimate and were nearly \$300 million.

8. If SoundExchange had followed the legislation, as written, SoundExchange would have sent out five checks to the major labels, distributing $70 \%$ of all royalties! Distributions to major independent labels would have increased pay through to $80 \%$ with about two hundred checks. It would then have been the label's responsibility to pay through royalties to their recording artists. Given the agreement by the major record labels to allow direct payment to their artists, the organization went from five checks to approximately 10,005 checks to distribute the same percentage of royalties. Furthermore, the organization found out quite quickly that an artist on a major label who hadn't had a hit recording in more than ten years, or who wasn't a major catalog seller (Sinatra, Ellington, Hank Williams, Sr.) was likely to have an old address or contact information that was stale, and many of these checks were returned creating a whole new level of work for staff.

9. SoundExchange collections in 2001 were about $\$ 3$ million and internal estimates had collections growing over the decade to approximately $\$ 80$ million in 2010 . Mechanical royalties in 2021 should be in the hundreds of millions of dollars even with direct licensing of services by the major music publishers.

10. Efforts to build a Global Repertoire Database or "GRD" were commenced in 2008 hosted by the World Intellectual Property Organization (WIPO) and included both collecting societies, music publishers, and companies in need of data: Google, Apple, and other music services. The effort was declared dead in July of 2014. See Klementina Milosic's Guest Op-Ed in Hypebot, "The Failure of the Global Repertoire Database," August, 31, 2015, https://www.hypebot.com/ hypebot/2015/08/the-failure-of-the-global-repertoiredatabase-effort-draft.html.

11. ISWC is an identifier used to specifically identify a composition, its authors, and publishers. More information about the International Standard Musical Works Code can be found at www.iswc.org. The ISRC or International Standard Recording Code is a unique identifier for sound recordings initially adopted in 1986. More information about ISRC codes can be found at www.isrc.com.

12. In the Copyright Office regulations governing SoundExchange, there was no obligation on SoundExchange's part to track down or find anyone! It was the sound recording copyright owner and featured artist's responsibility to come forward and register. Despite these regulations, SoundExchange expended considerable sums to proactively find those entitled to royalties. In doing so, "follow the dollar" is the most important principle to efficiently run your CMO: track down those owed the most first and then move down the list.

13. Barry Massarsky, a former ASCAP economist, took the census data SoundExchange was receiving from Satellite Services DMX, Music Choice, and Muzak, and created a sample that replicated what ASCAP and BMI would have received from broadcasters under the three-day per quarter methodology. SoundExchange was able to show the fundamental difference between services that were playing hundreds of recordings per channel on a broad range of channels and terrestrial broadcasters who had very narrow playlists in a very small number of genres.

14. Which labels rights were implicated? The country where a stream originated or the country where the stream was received? Many webcasters were streaming across national borders to listeners in other countries.

15. European copyright protection for sound recordings was fifty years from publication until 2012 when the term of protection was increased to seventy years. This meant that many classic recordings from the 1930 s to the 1950 s were in the public domain in the United Kingdom and Europe and were being reissued by labels who did not initially own the rights. In the United States, the protection of sound recordings was not covered under federal copyright until February 15,1972 , but state and common law protections were relied upon by owners to assert and protect rights. The only limitation on duration of these state and common 
law rights was the U.S. Copyright Law's proscription that all pre-1972 recordings would enter the public domain in 2067.

16. SoundExchange faced another major problem that the MLC will avoid: frequently in classical music the artist was listed as "Beethoven" or "Mozart" instead of listing the recording artist who had made the recording of Beethoven's or Mozart's works. These works are in the public domain so do not implicate mechanical royalties unless there are arrangement credits claimed.

17. SoundExchange received recording data that included Chinese characters as well as titles reported in other alphabets. Unless translators are hired, these payments may be tough to make especially if the overall numbers don't justify the expense of hiring foreign language experts.

18. This was a major theme at the June 26, 2019 oversight hearing referenced above. See Ed Christman's June 26, 2019 piece in Billboard titled, "House Judiciary Hearing on Copyright Office Reviews Music Modernization Act, Black Box Royalty Concerns," https://www. billboard.com/articles/business/8517787/house-judiciary-hearing-on-copyright-office-music-modernization-act.

19. Pandora was a great partner with SoundExchange in this regard. While Pandora and SoundExchange fought tooth and nail over rates to be paid, Pandora sent out notices when they accepted recordings that directed those artists and labels to register with SoundExchange as royalties would be earned from their Pandora activity.

20. Section 115(d)(3)(v) sets forth the provisions governing unclaimed royalties. A pertinent part of the statute states: "UNCLAIMED ROYALTIES OVERSIGHT COMMITTEE.-The board of directors of the mechanical licensing collective shall establish and appoint an unclaimed royalties oversight committee consisting of 10 members, 5 of which shall be musical work copyright owners and 5 of which shall be professional songwriters whose works are used in covered activities." This committee is tasked with creating rules for fair distribution of unclaimed royalties.

21. One of SoundExchange's greatest early challenges was created by the delay in setting webcasting rates. While webcasters were obligated to pay royalties as of October 28, 1998, no rates were set until June of 2002. When rates were set at seven hundredths of a penny per stream, $\$ .000762$, many webcasters ceased operations as they were hoping to pay percentage of revenue rates as they had little or no revenue. But of greater import, some of the largest streamers, AOL, MSN, and Yahoo, sent payments based upon usage with no accompanying data. When asked for the data, which was required by statute, they stated they had not kept it! How was SoundExchange to distribute these payments without data? The organization created a proxy from other data received that was thought to be similar to what was being streamed on those services and submitted it to the Copyright Office for approval. The Copyright Office then published this proposal to the music community at large, seeking comments. As there were no objections, it was approved. That proxy, obviously not exact, was better than market share distribution or nothing!

22. There were several instances during the early years of SoundExchange where an artist refused the royalties that were offered to them. Some thought SoundExchange was a scam (it did start at around the time that Nigerian oil money e-mails and Netherlands lottery winnings e-mails were quite the rage), though for others they simply didn't believe they'd earned the money!

23. Admin rates are determined by taking the total amount of a CMO's collections and then calculating their costs of collecting and distributing those collections. It is appropriate to include amortized costs of building technology solutions, costs of rate proceedings to set rates for specific licenses they administer, overhead, salaries of staff, and limited marketing costs necessary to publicize their efforts and to attract members (if membership is required or provides other benefits). In some countries, a percentage of collections is designated for anti-piracy efforts or cultural funds. These are quite controversial especially for international participants who may not benefit from cultural funds to support the arts in-country. For large CMOs admin rates should be under fifteen percent although admin fees will vary based upon which rights are being collected. Radio, television, and digital services are far easier and cheaper to collect than night clubs, restaurants, bars, and other locations subject to general licensing. 


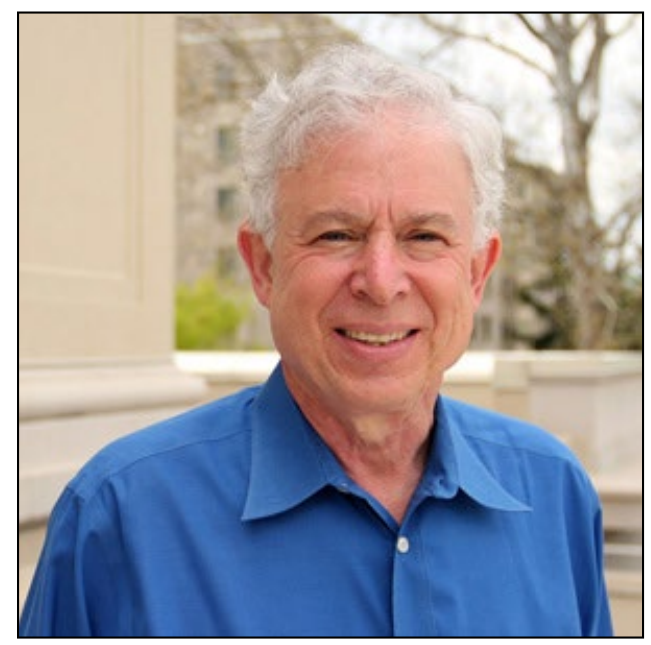

John Simson has been in the music industry since his signing in 1971 as a recording artist and songwriter. Simson's career has included stints as a manager, handling the career of five-time Grammy winner, Mary Chapin Carpenter, special advisor to Harry Belafonte for music and television projects, and a thirty-year career as an entertainment lawyer advising clients on copyright and business issues in film, television, music, and the visual arts. He most recently served as the Executive Director of SoundExchange from 2001-2010, an organization he helped launch in 2001. SoundExchange collects royalties from internet and satellite radio services on behalf of recording artists and record labels. The organization is now responsible for distributions greater than two billion dollars since inception. Simson received an Emmy nomination for his music supervision of the PBS series "American Roots Music" and was named the Outstanding Volunteer Lawyer by Washington Area Lawyers for the Arts on their tenth anniversary celebration. Simson was at the forefront of the battle for artist's rights and their ability to be paid for their work online and has been featured on NBC Nightly News, The New York Times, WSJ, Marketplace, CNN, and many other news outlets. He is a frequent lecturer on music industry and copyright issues and currently serves as the Chairman of the Board of the National Recording Preservation Board of the Library of Congress, is Chairman of the D.C. Bar's Art, Entertainment, Media \& Sports Law Committee, is a Board member of CINE, the Musicianship and the Music Manager's Forum. He is a 1994 Alumni of Nashville's Leadership Music Program and is a past President of the Washington, D.C. Chapter of the Grammy organization. Simson previously taught Entertainment Law at Washington College of Law and Georgetown University Law Center. He is currently Executive in Residence and Program Director for Business \& Entertainment in the Kogod School of Business at American University. 


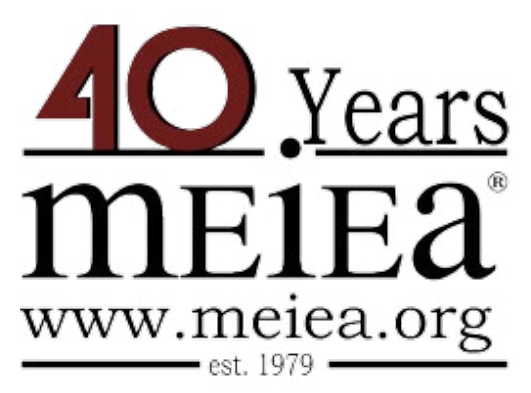

\section{PROCEEDINGS OF THE \\ 2019 INTERNATIONAL SUMMIT \\ OF THE \\ MUSIC \& ENTERTAINMENT \\ INDUSTRY EDUCATORS \\ ASSOCIATION}

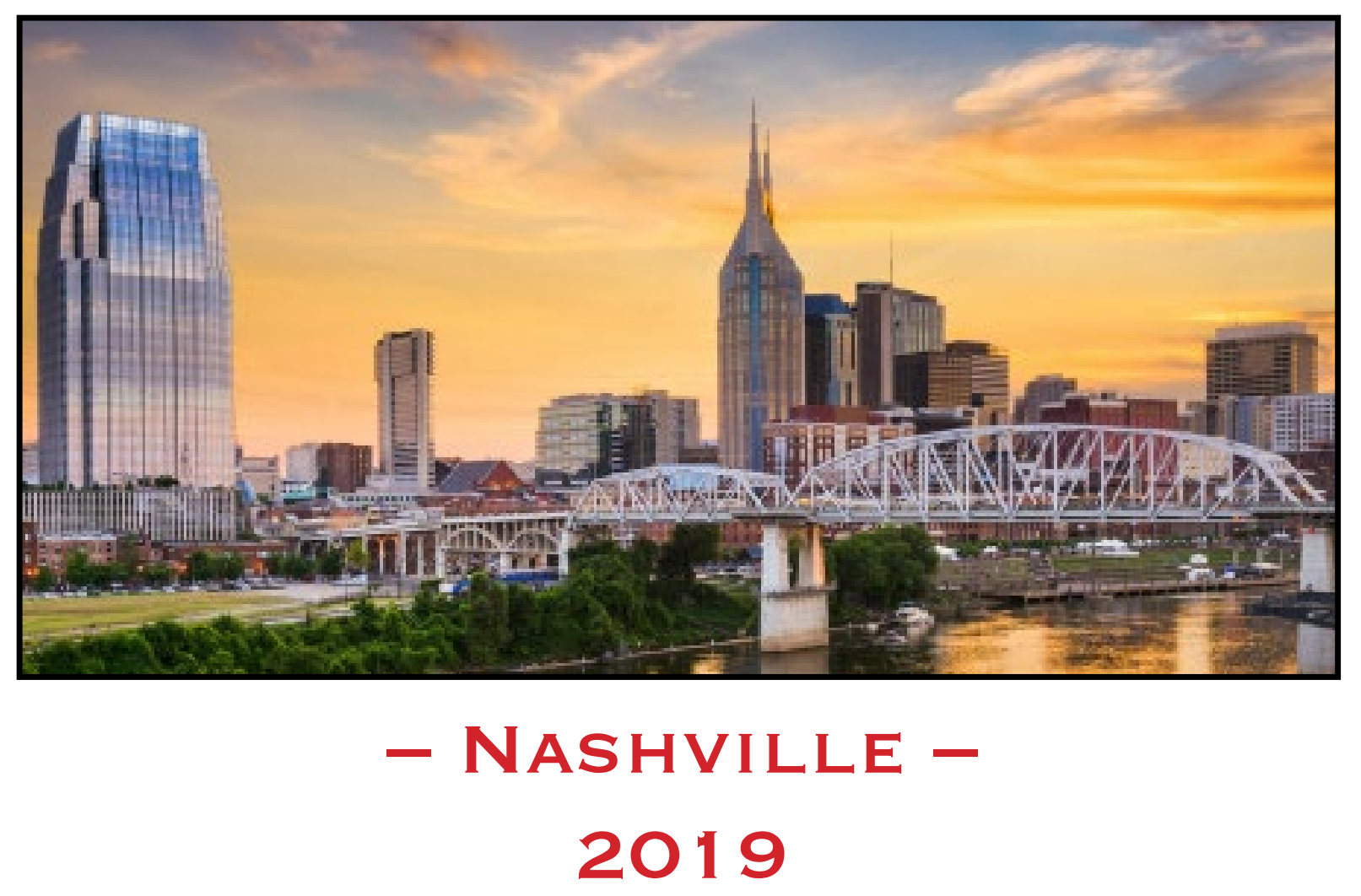

March 21 - 23, $2019 \cdot$ Belmont University - Nashville 